\title{
BMJ Open Do health literacy and patient empowerment affect self-care behaviour? A survey study among Turkish patients with diabetes
}

\author{
Ezgi Eyüboğlu, ${ }^{1}$ Peter J Schulz ${ }^{2}$
}

To cite: Eyüboğlu E, Schulz PJ. Do health literacy and patient empowerment affect self-care behaviour? A survey study among Turkish patients with diabetes. BMJ Open 2016;6:e010186. 010186

- Prepublication history for this paper is available online. To view these files please visit the journal online (http://dx.doi.org/10.1136/ bmjopen-2015-010186).

Received 7 October 2015 Revised 2 February 2016 Accepted 15 February 2016

CrossMark doi:10.1136/bmjopen-2015-

\section{ABSTRACT}

Objective: This study aimed to assess the impact of health literacy and patient empowerment on diabetes self-care behaviour in patients in metropolitan Turkish diabetes centres. The conceptual background is provided by the psychological health empowerment model, which holds that health literacy without patient empowerment comes down to wasting health resources, while empowerment without health literacy can lead to dangerous or suboptimal health behaviour.

Design, setting and participants: A cross-sectional study was conducted with 167 patients over the age of 18 from one of two diabetes clinics in a major Turkish City. Self-administered questionnaires were distributed to eligible outpatients who had an appointment in one of the clinics. Health literacy was measured by a newly translated Turkish version of the Short Test of Functional Health Literacy in Adults (S-TOFHLA) and the Chew self-report scale. Patient empowerment was measured by a 12-item scale based on Spreitzer's conceptualisation of psychological empowerment in the workplace. Self-care behaviour was measured by the Self-care behaviours were measured by the Summary of Diabetes Self-Care Activities Measure (SDSCA). Level of diabetes knowledge was measured by Diabetes Knowledge Test.

Results: Two subscales of empowerment, impact and self-determination, predicted self-reported frequency of self-care behaviours. Neither health literacy nor diabetes knowledge had an effect on self-care behaviours.

Conclusions: Health literacy might be more effective in clinical decisions while empowerment might exert a stronger influence on habitual health behaviours.

\footnotetext{
${ }^{1}$ Public Relations and Publicity Department, Maltepe University, Marmara Eğitim Köyü, Istanbul, Turkey ${ }^{2}$ Institute of Communication and Health, Universita' della Svizzera Italiana, Lugano, Switzerland
}

Correspondence to Ezgi Eyüboğlu;

ezgieyubogluphd@gmail.com

\section{BACKGROUND}

Health literacy has increasingly been recognised as a factor in health behaviours, healthcare and health itself. Research shows that low or inadequate health literacy is associated with poor adherence to medical regimens, poor understanding of health issues, a lack of knowledge about medical care and

\section{Strengths and limitations of this study}

- This is the first study in Turkey trying to get evidence about the effect of health literacy and patient empowerment on self-care behaviour in patients with diabetes in Turkey.

- This study enables better understanding of management behaviour in diabetes.

- The sample is not representative of the population of Turkish patients with diabetes.

conditions, poorer comprehension of medical information, low understanding and use of preventive services, poorer overall health status and earlier death. ${ }^{1-3}$ Furthermore, individuals with chronic diseases (eg, diabetes, high blood pressure and heart disease) and limited health literacy have less understanding of their disease and experience more negative outcomes than individuals with higher health literacy. ${ }^{4-10}$

Health literacy is defined as the 'degree to which individuals have the capacity to obtain, process, and understand basic health information and services needed to make appropriate health decisions ${ }^{11}$. The definition highlights the fact that health literacy is ability, but ability is not always implemented as behaviour. One can have the ability to make sound health decisions but still prefer to leave decisions to healthcare providers. Since some people may choose not to use their ability, others who do not have this ability may still claim to have a say in medical decisions.

This claim is sometimes captured in the concept of health empowerment. ${ }^{12}$ It is defined as the subjective feelings of power, control and self-esteem that make the patient value autonomy-and thus interest in and desire to participate in healthcare decisions. In this vein, patient empowerment is volitional. ${ }^{12}{ }^{13}$ According to Spreitzer, ${ }^{14}$ empowerment at the workplace has four 
dimensions: meaningfulness (or relevance), capturing the value of activities, judged in relation to an individual's own ideal of life; self-efficacy (or competence), the belief in one's capabilities to produce, by one's actions, the outcomes one desires; self-determination (or choice), the idea that one's decisions and choices are one's own, and not imposed by others; and finally impact, the notion that one can make a difference in the scheme of things. This concept was transferred to health empowerment, and an operationalisation of the concept into a 12-item scale ( 3 items by 4 dimensions) was successfully used in research. ${ }^{12} 13$

According to the health empowerment model, ${ }^{12}$ best outcomes will be achieved when the competence-based factor of health literacy coincides with the volitional factor of health empowerment. The model assumes that health literacy without empowerment comes down to a waste of resources: a person's actual ability to contribute to health protection and healthcare is not used because one does not think one can do much in this respect. Conversely, the model also holds that high empowerment without sufficient literacy may entice people to detrimental health behaviours: one claims to play an autonomous role in one's own healthcare but lacks the ability to know or learn what to do.

This article aims at contributing to studying the role of empowerment and health literacy together. It does so using data from a survey of Turkish patients with diabetes, which was primarily conducted to produce evidence of the reliability and validity of two health literacy measures translated from the original English into Turkish. ${ }^{15}$ The present analysis set out to test three hypotheses:

Hypothesis 1: The higher the patient's health literacy, the more appropriate self-care behaviours will they show.

Hypothesis 2: The higher the patient's health empowerment, the more appropriate self-care behaviours will they show.

Hypothesis 3: Most appropriate self-care behaviours will be shown by patients with both a high level of literacy and a high level of empowerment.

Hypothesis 3 states an interaction effect of health literacy and empowerment, which of course can be tested only when Hypotheses 1 and 2 are confirmed.

\section{METHODS}

\section{Sampling and procedure}

Data were collected between 30 May and 25 November 2013 from outpatients who had an appointment in one of two diabetes clinics in a major Turkish City. Self-administered paper-pencil questionnaires were distributed to outpatients who had been diagnosed with type 1 or type 2 diabetes and were 18 years or older. Patients were excluded if they had a severely impaired vision (20 patients). We approached 321 patients, 19 of whom refused to participate, leaving a sample of 302 at a response rate of $94 \%$. Owing to an irregularity in the application of one of the measures, 135 respondents had to be excluded from the analyses in this study, setting its sample at 167 patients.

Two collaborators trained in confidentiality, recruitment and data collection procedures distributed and collected the questionnaires. They explained the purpose of the study to the patients, and after obtaining oral consent, they asked the patients to fill in the questionnaire before their meeting with their doctor. Some patients were permitted to answer the questionnaire after seeing the doctor.

\section{Measures}

Two measures were employed for health literacy. First, the reading section of the Short Test of Functional Health Literacy in Adults ${ }^{16}$ (S-TOFHLA); and second, a set of four screening questions asking matters of respondents' self-perception. S-TOFHLA is one of the most widely used tests of functional literacy due to its strong reliability and validity data in English. Also, it was translated and validated in several languages such as Spanish, ${ }^{9}$ Chinese, ${ }^{17}$ Brazilian Portuguese, ${ }^{18}$ Serbian $^{19}$ and Hebrew. ${ }^{20}$ The reading comprehension part of S-TOFHLA includes two texts with altogether 36 gaps and, for each gap, a selection of four formulations to fill it. The first section is a text, written for the fourth grade level, on getting prepared for an upper gastrointestinal examination, while the other is about patient rights and responsibilities, written for the 10th grade level.

The S-TOFHLA ${ }^{9}$ questionnaire is to be operated with a 7 min time limit, which, however, was not enforced for 135 of the 302 persons originally in the sample. To ensure comparability, all analyses here are reported for the subsample which had the $7 \mathrm{~min}$ limit enforced $(\mathrm{n}=167)$.

Mistaking the questionnaire as a test, many participants wished to complete the measure beyond the $7 \mathrm{~min}$ limit. They were allowed to do so, but the items completed after the $7 \mathrm{~min}$ limit were, as a rule, not noted and not counted for the S-TOFHLA score.

The perception-based screening measure was composed of these items:

1. How often do you have someone help you read hospital materials?

2. How confident are you filling out medical forms by yourself?

3. How often do you have problems learning about your medical condition because of difficulty understanding written information?

4. How often do you have problems understanding what is told to you about your medical condition?

A total score for S-TOFLHA was formed by summing up the correct answers. It can run theoretically from 0 to 36 , and the distribution covered that total range. For the screening measure, the answer options were $1=$ never to 5 =always. The second item was reversed and an average score computed for every respondent. Table 1 shows the means and other descriptive information on these and other variables in the study. 
Table 1 Cronbach's $\alpha$ of the measures

\begin{tabular}{lll}
\hline Measurements & $\begin{array}{l}\text { Present } \\
\text { study }\end{array}$ & Original \\
\hline S-TOFHLA & 0.81 & 0.98 \\
Summary of Diabetes Self-Care & 0.71 & 0.80 \\
Activities Measure & & \\
Psychological Empowerment Scale & 0.87 & 0.71 \\
Diabetes Knowledge Scale & 0.74 & 0.89 \\
\hline S-TOFHLA, the Short Test of Functional Health Literacy in Adults.
\end{tabular}

Health empowerment was measured by Psychological Health Empowerment scale with 12 items, ${ }^{12} 13$ three for each of the four dimensions (meaningfulness, selfefficacy, self-determination, impact). This measurement was adapted to the field of health from Spreitzer's ${ }^{14}$ conceptualisation of psychological empowerment in the workplace. Patients were asked to answer the questions on a 7-point Likert scale ( $1=$ Strongly disagree, $7=$ Strongly agree).The items were factor analysed and two subscales emerged, one composed of three items on the dimension of impact, and the other composed of three items on self-determination.

Self-care behaviours were measured by the Summary of Diabetes Self-Care Activities Measure (SDSCA), ${ }^{21}$ which is a brief self-report questionnaire of diabetes selfmanagement. In this study, a version of SDSCA was used that included items assessing five aspects of the diabetes regimen: general diet (2 items), specific diet (2 items), exercise ( 2 items), blood glucose testing ( 2 items), and foot care ( 2 items). Two further items concern smoking behaviour were relevant to smokers only and therefore excluded from the analysis. The questionnaire enquired, for each item, on how many days a week a particular behaviour was performed. Answers ranged from 0 to 7. A composite score based on all 10 items was computed. General diabetes knowledge was measured with 6 true/false items; the number of correct answers was summed up, ranging from 0 to 6 .

Diabetes knowledge was measured by the Diabetes Knowledge Test, ${ }^{22}$ which consists of ten statements regarding type 1 and type 2 diabetes and the answer options 'yes', 'no' and 'don't know'.

The original English version of the S-TOFHLA, ${ }^{9}$ Chew, $^{23}$ the Health Empowerment Scale,, ${ }^{12}{ }^{13}$ the Diabetes Knowledge Test ${ }^{22}$ and the Summary of Diabetes Self-Care Activities Measure ${ }^{21}$ were translated by a philologist and native speaker of Turkish. Owing to differences in language structure, some of the gaps in the S-TOFHLA reading material had to be shifted to different places in the text. The translation was done with the aim that an average patient able to understand basic expressions would also be able to comprehend the text. Technical terms and any kind of jargon were avoided. Back translation was carried out by another philologist fluent in English to see whether differences between the original English and Turkish versions would arise.
Besides, cultural adaptation was taken into consideration during the whole translation process. The translation excluded the four numeracy items of the original S-TOFHLA version. A pretest was conducted with 120 participants which was independent from the main sample. By using cognitive interviewing, the pretest necessitated a few revisions. Table 1 shows the reliability of the measures in comparison with the original values.

The present study was conducted in collaboration with TUBITAK (Scientific and Technological Research Council of Turkey) and also approved by a committee from this institution.

\section{Data analysis}

The hypotheses were tested in three steps. First, bivariate correlations were computed (Pearson's r). Second, a linear regression model was computed with the composite self-care behaviours score as a dependent variable and the measures for health literacy, empowerment and knowledge as independent variables. Third, similar models were computed for each of the five individual self-care behaviours. Tests for significance were 1-tailed.

\section{RESULTS}

The sample is diverse and spreads well across gender, age groups, education groups and income. Table 2 shows the distribution of these variables, showing that women were over-represented.

The measured variables distribute mostly around means somewhat on the positive side of the scales, that is, towards frequent self-care behaviour, high literacy, high knowledge and high empowerment. Aside from the more or less normal distribution around the mean, some of the measures show a modal value (or a second modal) at the extreme positive end. Table 3 shows the details of the distributions. Since skewness and kurtosis were within the acceptable range, we decided that the use of Pearson's $r$ and linear regression modelling was justified.

Bivariate correlations show moderate relationships between empowerment and frequency of self-care

Table 2 Sociodemographic characteristics of the sample

\begin{tabular}{ll}
\hline & $(\mathbf{n}=167)$ \\
\hline Age-mean (SD) & $51.6(14.24)$ \\
Gender-female & $65.3 \%$ \\
Education (\%) & \\
$\quad$ <5th grade (elementary school) & 8.4 \\
6th-8th grades (secondary school) & 9.0 \\
9th-11th grades (High school) & 41.9 \\
$\quad$ University & 40.7 \\
Marital status_\% married & 79.6 \\
Income in Turkish Lira (\%) & \\
$\quad<775$ & 8.4 \\
776-1500 & 24.0 \\
1501-2500 & 27.5 \\
$>2500$ & 37.7 \\
\hline
\end{tabular}


Table 3 Overview of variables

\begin{tabular}{|c|c|c|c|c|c|c|}
\hline & Range & M & SD & Skewness & Kurtosis & $\alpha$ \\
\hline $\begin{array}{l}\text { 1. Self-perceived frequency of self-care behaviours, composite } \\
\text { score }\end{array}$ & $0-7$ & 3.7 & 1.39 & -0.17 & -0.34 & 0.76 \\
\hline 2. Health literacy, S-TOFHLA & $0-36$ & 17.3 & 11.24 & 0.85 & -1.37 & NA \\
\hline 3. Health literacy, screening scale & $1.25-5.00$ & 4.1 & 0.72 & -0.89 & 0.85 & 0.75 \\
\hline 4. Diabetes knowledge & $0-6$ & 3.6 & 1.19 & -0.56 & 0.51 & NA \\
\hline 5. Health empowerment: impact & $1.5-7.0$ & 5.6 & 1.18 & -1.01 & 0.93 & 0.81 \\
\hline 6. Health empowerment: self-determination & $1.0-7.0$ & 5.0 & 1.48 & -0.43 & -0.53 & 0.70 \\
\hline
\end{tabular}

behaviours, as hypothesised. The correlations between health literacy and self-care behaviours, however, did not reach significance. Hypothesis 2, pertaining to patient empowerment, was thus confirmed, while Hypothesis 1, pertaining to health literacy, was not supported. Table 4 gives the correlation coefficients in overview.

In addition, table 4 reveals that the two measures of health literacy were relatively strongly related, and so were the two measures of health empowerment. Second, the screening measure of health literacy was correlated with both empowerment measures, but S-TOFHLA was not related to either. That means that the two independent variables were related, but only for the screening measure of health literacy. Third, diabetes knowledge (similar to health literacy) was unrelated to frequency of self-care behaviours, and there was a relationship between knowledge and the screening literacy indicator. Fourth, diabetes knowledge and the empowerment dimensions of impact and self-determination were correlated.

The final step in the analyses is linear regression models, controlled for gender, age and education (not shown), to assess the relative contributions of literacy,

Table 4 Bivariate correlations

\begin{tabular}{|c|c|c|c|c|c|}
\hline & 2 & 3 & 4 & 5 & 6 \\
\hline $\begin{array}{l}\text { 1. Self-perceived } \\
\text { frequency of } \\
\text { self-care } \\
\text { behaviours, } \\
\text { composite score }\end{array}$ & 0.01 & 0.06 & 0.11 & $0.39^{\star \star \star}$ & $0.30^{\star * *}$ \\
\hline $\begin{array}{l}\text { 2. Health literacy, } \\
\text { S-TOFHLA }\end{array}$ & & $0.32^{\star \star \star}$ & 0.05 & 0.02 & 0.08 \\
\hline $\begin{array}{l}\text { 3. Health literacy, } \\
\text { screening scale }\end{array}$ & & & $0.16^{\star}$ & $0.31^{\star \star \star}$ & $0.21^{\star *}$ \\
\hline $\begin{array}{l}\text { 4. Diabetes } \\
\text { knowledge }\end{array}$ & & & & $0.31^{\star \star \star}$ & $0.18^{*}$ \\
\hline $\begin{array}{l}\text { 5. Health } \\
\text { empowerment: } \\
\text { impact }\end{array}$ & & & & & $0.53^{\star \star *}$ \\
\hline $\begin{array}{l}\text { 6. Health } \\
\text { empowerment: } \\
\text { self-determination }\end{array}$ & & & & & \\
\hline
\end{tabular}

empowerment and knowledge to self-care behaviour in patients with diabetes. The first regression model uses the composite score of self-reported frequency of selfcare behaviour as a dependent variable and is shown in the first column in table 5 . The result is straightforward and clear: no independent variable has an effect on outcome beyond the effect of the impact dimension of health empowerment. It is especially clear that health literacy and knowledge have no independent effect on the frequency of self-care behaviour. Therefore, no interaction terms were entered into the regression analysis, as the bivariate correlations had already suggested.

Table 5 shows results from similar regressions with the self-perceived frequency of single self-care behaviours as dependent variables. There are only a few findings that deviate from the results for the composite score. When the frequency of following the demands of a diabetes specific dieting behaviour is analysed, the predictive power of the empowerment dimension of impact becomes weaker but is still marginally significant. Measuring blood sugar and foot care is not predicted by any of the independent variables. By and large, these regressions confirm the result obtained by regressing the composite score on the independent variables.

\section{DISCUSSION}

The most important result is that Hypothesis 2 was confirmed: health empowerment and, in particular, its dimensions of impact and self-determination are significant predictors of the self-perceived frequency of selfcare behaviour in Turkish patients with diabetes, though self-determination has no effect beyond impact. However, Hypothesis 1, which stated a similar role for health literacy, could not be supported at all. As a result, Hypothesis 3 could not be pursued in the analysis, and nothing can be said about an interaction effect of health literacy and empowerment on self-care behaviour.

This result could indicate that diabetes self-care behaviours are so easily understood by patients or so well related to patients that health literacy makes no difference. In other words, it does not require higher cognitive abilities to understand the advice or instructions given by healthcare professionals on self-care, or selfcare behaviour is explained so well that the limits of lower levels of health literacy are overcome. The 
Table 5 Regression of frequency of self-care behaviours

\begin{tabular}{|c|c|c|c|c|c|c|}
\hline & $\begin{array}{l}\text { Frequency of self-care } \\
\text { behaviours, composite } \\
\text { score }\end{array}$ & $\begin{array}{l}\text { General } \\
\text { dieting }\end{array}$ & $\begin{array}{l}\text { Specific } \\
\text { dieting }\end{array}$ & Exercise & $\begin{array}{l}\text { Measuring } \\
\text { blood sugar }\end{array}$ & $\begin{array}{l}\text { Foot } \\
\text { care }\end{array}$ \\
\hline $\begin{array}{l}\text { Health empowerment: } \\
\text { impact }\end{array}$ & $0.278^{\star \star}$ & $0.424^{\star \star \star}$ & $0.169 \#$ & $0.239^{\star \star}$ & 0.062 & 0.120 \\
\hline $\begin{array}{l}\text { Health empowerment: } \\
\text { self-determination }\end{array}$ & $0.151 \#$ & 0.017 & 0.127 & $0.187^{\star}$ & 0.080 & 0.132 \\
\hline Diabetes knowledge & 0.019 & 0.003 & 0.053 & -0.046 & 0.086 & -0.036 \\
\hline $\begin{array}{l}\text { Health literacy, } \\
\text { S-TOFHLA }\end{array}$ & 0.045 & -0.042 & -0.023 & 0.096 & -0.061 & 0.138 \\
\hline $\begin{array}{l}\text { Health literacy, screening } \\
\text { scale }\end{array}$ & -0.041 & 0.023 & -0.107 & -0.113 & -0.002 & -0.058 \\
\hline $\mathrm{R}^{2}$ & $(0.20)$ & $(0.22)$ & $(0.09)$ & $(0.17)$ & $(0.12)$ & $(0.10)$ \\
\hline
\end{tabular}

opposite could also be true: self-care advice is so complicated or so badly communicated that even patients with high levels of health literacy do not get it. The high level of compliance with self-care advice, however, speaks against this interpretation.

Next, the influence of the empowerment dimension of impact suggests that frequent self-care behaviour goes along with the subjective impression that it matters. This is not necessarily evidence of an effect of the impression (ie, empowerment) on the behaviour. It might just be the other way round and the causal direction might be reversed. Some patients trying out the dieting and exercise advice they are given will find that the advice is good for them, while others might not experience such benefits. The former would come to believe that their behaviour matters, while the latter would not draw such conclusions. Rather than seeing self-care behaviour as a consequence of empowerment (as the study design had assumed), this interpretation conceives of empowerment as a consequence of experience, at least as far as the dimension of impact is concerned.

The other dimension of empowerment in the study, self-determination or choice, aims at the subjective impression that one is free to choose among various behavioral alternatives. That this impression was hardly related to self-care behaviours in the regression analyses might have to do with the high demands that a chronic disease such as diabetes puts on patients. The impression that one has a choice in dealing with diabetes might very well clash with patients' experience of the demands and restrictions. Patients will get more advice the more severe their condition becomes, ${ }^{24}{ }^{25}$ and some will just be more sensitive than others to the restrictions that go along with advice. An objectively or subjectively high amount of advice can easily be perceived as restricting one's choice ${ }^{2627}$ while at the same time the advice is followed, but not out of a sense of choice but of duty, or experience, or a sense of compliance. A large amount of advice might thus have differential effects on behaviour and one's sense of choice. This would mitigate the possible relationship between a sense of choice and beneficial self-care behaviours.

Looking at the different aspects of self-care, measuring blood glucose levels and foot care was found to be less predictable than general and specific dieting and exercise. This might be explained by an effect of necessity on the frequency of behaviour. At a certain level of severity, the diabetes condition requires frequent measuring of glucose levels ${ }^{28-30}$ and bad experience might entice patients to examine their feet regularly. ${ }^{30}$ Inasmuch as medical necessity impacts the frequency of these two behaviours, the potential for an effect of a volitional factor such as empowerment will be reduced. Something similar might be at work with the reduced influence on specific dieting compared to general dieting: following specific dieting advice might be more often dictated by medical necessity than following general advice.

The differential impact of empowerment and health literacy found in this study highlights a difference in outcomes that might be related to the two factors. Health literacy aims at the ability to understand medical subjects in order that patients can take a higher share in decisionmaking, mostly in decisions about therapy. It might therefore be strongly linked to outcomes that have to do with medical decision-making. Empowerment, on the other hand, aiming at factors such as self-perceived choice, perceived self-efficacy and the self-assessed consequences of health behaviour, seems much better suited to explain habitual behaviour. The outcome in this study, diabetes self-care, belongs to habitual behaviours. This could explain why empowerment had an effect on this outcome and health literacy had none.

Knowledge was found to be more strongly related to empowerment than to health literacy. This is a surprising result because knowledge is often conceived of as a dimension of health literacy, ${ }^{17}$ and some very common measures of health literacy such as the REALM ${ }^{31}$ can be interpreted as knowledge tests. This could arise from a particular quality of the illness. Since it chronically 
affects people's life, diabetes self-care requires to consider both metabolic and lifestyle factors. So patients make many diabetes-related choices in their daily lives that enable them to find out the healthiest options by experience. Knowledge obtained in that way may change the motivational skills of patients in a positive way. The way patients get informed about their illnesses by experience, which may be the most common among patients with diabetes, could motivate people to become more empowered.

The perception-based screening question was more strongly linked with the other independent variables of knowledge and empowerment than the performancebased S-TOFHLA. Correlation between these variables, though not the focus of this study, is expected. That the Turkish translation of S-TOFHLA produces no correlation with knowledge, empowerment or outcomes might make one question the validity of the instrument. An earlier study, ${ }^{15}$ however, which was based on the same data set as the present article, found broad evidence of construct validity by correlating the measure with known predictors of health literacy. ${ }^{3-5}{ }^{32}$ The lack of correlations in the analysis reported in this article calls for putting the measure to the test again and having another look into this matter, based on new data.

This study was motivated by presenting empirical evidence for a key feature of the health empowerment model: the necessity of both high health literacy and high empowerment for reaching a beneficial level of patient involvement in healthcare decisions and behaviours. The study, however, found that for diabetes selfcare, health literacy did not matter much, while empowerment did. This suggests that patients with the desire to get involved do not necessarily have to show higher levels of health literacy to avoid risking making mistakes. The role of dangerous self-managers, conceived in the model as persons with high empowerment and low literacy, appears to be contingent on conditions which need to be conceptually and empirically studied in more depth.

That the self-care behaviour of patients with type 1 and type 2 diabetes was measured with the same items and scales counts among the limitations of this study. The selfcare behaviours in question apply, in one form or another, to both groups of patients, but in detail different recommendations may be made to them. Therefore similar behaviours might be right for some patients and wrong for others. A more specified consideration is necessary. In addition, it cannot be completely ruled out that leaving out the smoking items from the SDSCA would not affect the psychometric properties of the measure.

\section{CONCLUSION}

The findings of this study suggest that empowerment affects habitual self-management behaviours. Patients with chronic conditions may need motivational skills more badly than reading skills to manage their diseases.
Twitter Follow Ezgi Eyüboğlu at @ezgiey

Acknowledgements The authors thank the Lugano University Institute of Communication and Health and TUBITAK (Scientific and Technological Research Council of Turkey) for funding this research. They are also thankful for the Turkish Diabetes Foundation's kind support during the data collection process.

Contributors Both authors of this article designed this study. EE arranged a meeting with the patients with diabetes and conducted the questionnaire. PJS carried out the data analyses and reported the initial findings. Both authors contributed to the discussion and conclusion parts.

Funding This research received no specific grant from any funding agency in the public, commercial or not-for-profit sectors.

Competing interests None declared.

Patient consent Obtained.

Ethics approval Turkish Diabetes Foundation.

Provenance and peer review Not commissioned; externally peer reviewed.

Data sharing statement No additional data are available.

Open Access This is an Open Access article distributed in accordance with the Creative Commons Attribution Non Commercial (CC BY-NC 4.0) license, which permits others to distribute, remix, adapt, build upon this work noncommercially, and license their derivative works on different terms, provided the original work is properly cited and the use is non-commercial. See: http:// creativecommons.org/licenses/by-nc/4.0/

\section{REFERENCES}

1. Pleasant A. Health literacy: an opportunity to improve individual, community, and global health in adult education for health and wellness. In: Imel S, Ross-Gordon JM. New directions for adult and continuing education. Wiley Inc, 2011:130:43-53.32:313-333.

2. Berkman ND, Sheridan SL, Donahue KE, et al. Low health literacy and health outcomes: an updated systematic review. Ann Intern Med 2011;155:97-107

3. Williams MV, Baker DW, Honig EG, et al. Inadequate literacy is a barrier to asthma knowledge and self-care. Chest 1998;114:1008-15.

4. Gazmararian JA, Williams MV, Peel J, et al. Health literacy and knowledge of chronic disease. Patient Educ Couns 2003;51:267-75.

5. Schillinger D, Grumbach K, Piette J, et al. Association of health literacy with diabetes outcomes. JAMA 2002;288:475-82.

6. Spandorfer JM, Karras DJ, Hughes LA, et al. Comprehension of discharge instructions by patients in an urban emergency department. Ann Emerg Med 1995;25:71-4.

7. Williams MV, Parker RM, Baker DW, et al. Inadequate functional health literacy among patients at two public hospitals. JAMA 1995;274:1677-82.

8. Kalichman SC, Benotsch E, Suarez T, et al. Health literacy and health- related knowledge among persons living with HIV/AIDS Am J Prev Med 2000;18:325-31.

9. Baker DW, Williams MV, Parker RM, et al. Development of a brief test to measure functional health literacy. Patient Educ Couns 1999;38:33-42.

10. Kalichman SC, Rompa D, Cage M. Reliability and validity of self-reported CD4 lymphocyte count and viral load test results in people living with HIV/AIDS. Intern J STD AIDS 2000;11:579-85.

11. Selden CR, Zorn M, Ratzan SC, et al. National library of medicine current bibliographies in medicine: health literacy. NLM Pub. No. CBM 2000-1. Bethesda, MD: National Institutes of Health, U.S. Department of Health and Human Services, 2000.

12. Schulz PJ, Nakamoto K. Health literacy and patient empowerment in health communication: the importance of separating conjoined twins. Patient Educ Couns 2013;90:4-11.

13. Camerini L, Schulz PJ. Effects of functional interactivity on patients' knowledge, empowerment, and health outcomes: An experimental model-driven evaluation of a web-based intervention. J Med Intern Res 2012;14:e105.

14. Spreitzer GM. Psychological empowerment in the workplace: dimension measurement and validation. Acad Manag J 1995;38:1442-507.

15. Eyüboğlu E, Schulz PJ. Validation of Turkish health literacy measures. Health Promot Int 2015. 
16. Rudd RE, Keller DB. Health literacy: new developments and research. J Comm Healthcare 2009;2:240-57.

17. Tang $\mathrm{YH}$, Pang SMC, Chan MF, et al. Health literacy, complication awareness, and diabetic control in patients with type 2 diabetes mellitus. J Adv Nurs 2008;62:74-83.

18. Carthery Goulart MT, Anghinah R, Areza-Fegyveres R, et al. Performance of a Brazilian population on the test of functional health literacy in adults. Rev Saude Publica 2009;43:631-8.

19. Jovic-Vranes A, Bjegovic-Mikanovic V, Marinkovic J. Functional health literacy among primary health-care patients: data from the Belgrade pilot study. J Public Health 2009;31:490-5.

20. Baron-Epel O, Balin L, Daniely Z, et al. Validation of a Hebrew health literacy test. Patient Educ Couns 2007;67:235-9.

21. Toobert DJ, Hampson SE, Glasgow RE. The summary of diabetes self-care activities measure: results from 7 studies and a revised scale. Diabetes Care 2000;23:943-50.

22. Fitzgerald JT, Funnell MM, Hess GE, et al. The reliability and validity of a brief diabetes knowledge test. Diabetes Care 1998;21:706-10.

23. Chew LD, Bradley KA, Boyko EJ. Brief questions to identify patients with inadequate health literacy. Fam Med 2004;36:588-94.

24. Larkey LK, Hecht ML, Miller K, et al. Hispanic cultural norms for health-seeking behaviors in the face of symptoms. Health Educ Behav 2001;28:65-80.
25. Coffman MJ, Norton CK, Beene L. Diabates symptoms, health literacy, and health care use in adult Latinos with diabetes risk factors. J Cult Divers. 2012;19:4-9.

26. Tsai TI, Lee SY, Tsai YW. Explaining Selected Behaviors in a national sample of Taiwanese adults. Health Promot Int 2015;30:563-72.

27. Shrivastava SR, Shrivastava PS, Ramasamy J. Role of self care management of diabetes mellitus. J Diabetes Metab Disord 2013;12:14.

28. Duke SA, Colagiuri S, Colagiuri R. Individual patient education for people with type 2 diabetes mellitus. Cochrane Database Syst Rev 2009;(1):CD005268

29. Arnold MS, Butler PM, Anderson RM, et al. Guidelines for facilitating a patient empowerment program. Diabetes Educ 1995;21:308-12.

30. Funnel MM, Brown TL, Childs BP, et al. National standards for diabetes self-management education. Diabetes Care 2011;34:589-96.

31. Davis TC, Long SW, Jackson RH, et al. Rapid estimate of adult literacy in medicine: a shortened screening instrument. Fam Med 1993;25:391-5.

32. Arnold CL, Davis TC, Berkel HJ, et al. Smoking status, reading level, and knowledge of tobacco effects among low-income pregnant women. Prev Med 2001;32:313-20. 